\title{
Enfermagem Obstétrica: um olhar brasileiro na humanização do nascimento e na esperança de dias melhores
}

\author{
Zaida Aurora Sperli Geraldes Soler**
}

A palavra "Natal" significa nascimento e os católicos comemoram em 25 de dezembro o nascimento de Jesus Cristo; no simbolismo das festas - presépios, árvores ornamentadas, luzes e presentes -, fica ressaltado seu significado de amor, benevolência, caridade, esperança de justiça e de humanização. Ao longo de 40 anos de vida profissional venho estudando e pesquisado as questôes que envolvem a humanização do nascimento e a atuação do enfermeiro obstetra/ obstetriz, como apresento a seguir [1].

No enfoque obstétrico, a denominação $\mathrm{Hu}$ manização foi adotada oficialmente no Brasil a partir de 2000, junto ao Programa de Humanização do Pré-Natal e Nascimento (PHPN), com o sentido de Equidade/Cidadania. Fala-se mais na humanização do parto, o que é um equívoco, já que o parto é um momento, envolve os períodos clínicos do parto. O nascimento é um processo, pois se relaciona a um preparo pré-concepcional ou no mínimo referente à gestação, trabalho de parto, parto, puerpério e atenção ao recém-nascido e lactente.

Do ponto de vista do cuidado profissional em Obstetrícia, ser "humano" significa ter emoçóes, capacidade de se importar, de se colocar na situaçáo do outro, de agir com respeito e competência (conhecimentos, habilidades, atitudes, valores e emoçôes), segundo as melhores evidências científicas. Se não há humanização há violência obstétrica e são muitas suas faces e apresentaçóes, entre outras: negar informaçōes ou fazer esclarecimentos que fogem à compreensão da mulher; o tratamento descortês, bruto, raivoso; a falta de interesse em preservar o pudor das parturientes; não se atender de forma oportuna e eficaz as emergências obstétricas; alterar o processo natural do parto com técnicas de aceleração, sem necessidade e consentimento informado da mulher; realizar cesárea, quando há condiçóes de parto normal; obrigar a mulher a parir deitada; criar obstáculos para o contato precoce mãe/filho, sem causa médica justificável. Privilegia-se na atenção obstétrica o prático, o cômodo, o mais rápido, mas não o mais simples, de menor custo e mais seguro, camuflando-se a violência nas normas, rotinas, preceitos e atitudes $\mathrm{da}$ equipe, com o interesse principal em facilitar o trabalho na instituição [1-6].

A cesárea eletiva tem representado a violência obstétrica mais evidente no Brasil, contribuindo para o seu aumento a medicalização do processo gravidez-parto; o pré-natal baseado na biomedicina; o medo da dor; experiências anteriores vividas ou relatadas; a conveniência da data marcada e um processo de negociação/orientação que se estabelece entre a gestante, seus familiares e o profissional médico [7]. A prematuridade é outra preocupação relacionada aos índices abusivos de cesarianas, figurando entre os maiores

** Obstetriz, enfermeira, mestre, doutora e livre-docente em enfermagem obstétrica, docente da graduação e pós-graduação lato sensu e stricto sensu na FAMERP, organizadora e coordenadora de cursos de especialização em enfermagem obstétrica na FAMERP, coordenadora geral do Programa de Pós-Graduação em Enfermagem - Mestrado Acadêmico - Capes, na FAMERP 
problemas da obstetrícia contemporânea, mesmo com os avanços terapêuticos e assistenciais [8].

Muitos estudos em todo o mundo ressaltam que é imprescindível a formação e atuação de obstetrizes/enfermeiros obstetras para o alcance de maiores índices de partos normais e sua atuação é muito valorizada em muitos países, em especial nos mais desenvolvidos. No Brasil, entretanto, ao longo do tempo tais profissionais foram perdendo lugar e são reveladas dificuldades de trabalho por confrontos e conflitos com a equipe médica [1]. Mesmo com as dificuldades enfrentadas, geralmente o enfermeiro obstetra tem participação mais efetiva, buscando preservar a autonomia e protagonismo da mulher, oferecendo cuidado solidário, sem perder a qualidade da assistência $[1,9]$.

No Brasil é necessário maior reconhecimento das competências, legitimidade, legalidade, autonomia e valorização na atuação do enfermeiro obstetra na assistência a mulher durante o ciclo gravídico-puerperal. As profissóes de parteira, obstetriz e enfermeira obstétrica são diferenciadas quanto à origem de formação profissional. Parteira é o título mais antigo, seguido de obstetriz, depois enfermeira-obstétrica e mais recentemente enfermeira (o) obstetra. $\mathrm{O}$ termo obstetra é usado como adjetivação da titulação de especialista na área, mostrando, nas diferentes denominações, as nuances na legislação de ensino e de exercício da profissão [10].

Chama a atenção o fato de associações médicas e muitos obstetras defenderem intervençôes que não têm respaldo científico e dificultar o trabalho de enfermeiros obstetras na atenção a mulheres no decorrer do ciclo gravídico- puerperal, em especial no trabalho de parto e no parto de mulheres de baixo risco obstétrico. Só é possível entender as dificuldades colocadas pela equipe médica contra a atuação de enfermeiros obstetras do ponto de vista corporativista, já que as evidências científicas mundiais são irrefutáveis quanto ao papel que assumem na humanização do nascimento e de maior resolução do parto normal/natural $[1,2]$.

Os confrontos e conflitos existentes na assistência ao parto por enfermeiro obstetra envolvem aspectos de dominaçáo e poder por parte da equipe médica, mas é inquestionável o maior enfoque de humanização do parto na sua assistência por enfermeiro. Mesmo com respaldo legal e ético, a assistência ao parto por enfermeiro obstetra é motivo de conflitos, em especial no que se refere aos limites de atuaçáo do enfermeiro e do médico. É importante colocar em pauta tais conflitos, identificando-os e discutindo-os, além de investir no trabalho em equipe e dispor de protocolos claros, definindo limites de responsabilidades, segundo área profissional [1,8-20].

Que em 2016 alcancemos maiores índices de atuação compartilhada do enfermeiro obstetra e de humanizaçáo do nascimento. Nosso caminhar tem sido muito lento, com poucos avanços e muitos recuos, mas nossa esperança não esmorece.

\section{Referências}

1. Soler ZASG. CEHPAN - Centro de Preparo e Assistência Humanizados ao Nascimento uma proposta para a região de São José do Rio Preto, São Paulo [tese livre-docência]. São José do Rio Preto: Faculdade de Medicina de São José do Rio Preto; 2005.

2. Benítez GG. Violencia obstétrica: [Editorial]. Rev Fac Med (Caracas) 2008;31(1):5-6.

3. Sodré TM, Merighi MAB, Bonadio IC. Escolha informada no parto: um pensar para o cuidado centrado nas necessidades da mulher. Cienc Cuid Saúde 2012;11(Suppl):115-20.

4. Diniz CSG. Humanização da assistência ao parto no Brasil: os muitos sentidos de um movimento. Ciênc Saúde Coletiva 2005;10(3):627-37.

5. Almeida JS, Silva DA, Soler ZASG. A taxa de disponibilidade para o parto: outra violência obstétrica? [Editorial]. Revista Enfermagem Brasil 2015;14(1):34.

6. Behruzi R, Hatem M, Goulet L, Fraser WD. Perception of humanization of birth in a highly specialized hospital: let's think differently. Health Care Women Int 2014;35(2):127-48.

7. Cardoso JE, Barbosa RHS. O desencontro entre desejo e realidade: a indústria da cesariana entre mulheres de camadas médias no Rio de Janeiro, Brasil. Physis (Rio J) 2012;22(1):35-52.

8. Progianti JM, Mouta RJO. A enfermeira obstétrica: agente estratégico na implantação de práticas do modelo humanizado em maternidades. Rev Enferm UERJ 2009;17(2):165-9.

9. Rocha CR, Fonseca LC. Assistência do enfermeiro obstetra à mulher parturiente: em busca do respeito à natureza. Rev Pesq Cuid Fund [Online] 2010;2(2):807-16. 
10. Riesco MLG, Tsunechiro MLG. Formação profissional de obstetrizes e enfermeiras obstétricas: velhos problemas ou novas possibilidades? Estudos Feministas 2002;10:449-59.

11. Vieira BDG, Moura MAV, Alves VH, Rodrigues DP. As implicaçóes da prática profissional de enfermeiros obstetras egressos da EEAN: a qualidade da assistência. Rev Pesqui Cuid Fundam [Online] 2013;5(4):408-16.

12. Rabelo LR, Oliveira DL. Percepçôes de enfermeiras obstétricas sobre sua competência na atenção ao parto normal hospitalar. Rev Esc Enferm USP 2010;44(1):213-20.

13. Prata JA, Progianti JM, Pereira ALF. O contexto brasileiro de inserção das enfermeiras na assistência ao parto humanizado. Rev Enferm UERJ 2012;20(1):105-10.

14. Garcia SAL, Lippi UG, Garcia SAL. O parto assistido por enfermeira obstetra: perspectivas e controvérsias. Rev Bras Prom Saúde [Impr] 2010;23(4).

15. Rocha CR, Fonseca LC. Assistência do enfermeiro obstetra à mulher parturiente: em busca do res- peito à natureza. Rev Pesq Cuid Fund. [Online] 2010,2(2):807-16.

16. Narchi NZ, Cruz EF, Gonçalves R. O papel das obstetrizes e enfermeiras obstetras na promoção da maternidade segura no Brasil. Ciênc Saúde Coletiva 2013;18(4):1059-68.

17. Sena CD, Santos TCS, Carvalho CMF, Sá ACM, Paixão GPN. Avanços e retrocessos da enfermagem obstétrica no Brasil. Rev Enferm UFSM 2012;2(3):523-9.

18. Velasque EAG, Pradebon VM, Cabral FB. O enfermeiro no processo parir/nascer: estratégia de cuidado e humanizaçáo do parto. Rev Enferm UFSM 2011;1(1):80-7.

19. Versiani CC, Rodrigues AK, Silva TCB, Holzmann APF, Souto DF. O ser enfermeiro obstetra no cuidade ao parto. Rev APS 2013;16(2):173-9.

20. Dodou HD, Rodrigues DP, Guerreiro EM, Guedes MVC, Lago PN, Mesquita NS. The contribution of the companion to the humanization of delivery and birth: perceptions of puerperal women. Esc Anna Nery Rev Enferm 2014; 18(2):262-269. 